\title{
Pyrene modification leads to increased catalytic activity in minimal hammerhead ribozymes $\dagger$
}

\author{
Verena Looser, ${ }^{a}$ Simon M. Langenegger, ${ }^{b}$ Robert Häner ${ }^{b}$ and Jörg S. Hartig*a \\ Received (in Cambridge, UK) 20th July 2007, Accepted 7th August 2007 \\ First published as an Advance Article on the web 14th August 2007 \\ DOI: 10.1039/b711170c
}

\begin{abstract}
Highly active variants of minimal hammerhead ribozymes are generated by the replacement of substantial parts of stem-loop structures with pyrene building blocks.
\end{abstract}

The hairpin is one of the most common and most important secondary structural motifs found in nucleic acids. ${ }^{1}$ In functional RNA it is an essential element for adopting the proper threedimensional structure. ${ }^{2}$ Due to the prominent role of the hairpin motif, the generation and study of hairpin mimics has been a topic of thorough investigation. The hairpin loop has been replaced with aliphatic linkers ${ }^{3}$ as well as with various types of aromatic ${ }^{4}$ and metal-coordinating derivatives. ${ }^{5}$ Stem-loop structures altered in this way were shown to possess interesting electronic and structural properties. ${ }^{4 a, b, d, e, 5 b, 6}$ Thus, hairpin mimics should be well suited for elucidating the role of stem-looped domains of functional nucleic acids. Often, stem-loops are mainly needed to add stability to the functional fold. ${ }^{7}$ On the other hand, such elements may also be engaged in other functions, such as tertiary interactions. Deletion of nucleotides is a commonly used method to address the function of a particular domain. This approach, however, is hampered by the fact that both, the contribution to the stability of a certain fold, as well as possible other functions may be affected simultaneously. Hairpin mimics could serve as ideal substitutes of stem-loop structures within a functional RNA and substitutions of this kind should provide an answer if the stem-loop is necessary for stability reasons or if it is additionally involved in critical tertiary interactions. In the present work, we demonstrate that hairpin mimics are able to displace stem-loops while maintaining the overall stability and activity of the fold. To our knowledge, this is the first report of hairpin mimics being used to replace substantial hairpins within the context of a functional RNA while maintaining its activity.

The minimal hammerhead ribozyme (HHR) represents an excellent model for a functional RNA since it consists of a small, well characterized motif. Moreover, its functionality can be monitored easily by determining the cleavage rate. The stability of the three stems flanking the ribozyme core is critical for folding and, hence, for cleavage activity in minimal hammerhead motifs. ${ }^{8}$ Recent studies have shown that close proximity of stem-loops I and II facilitated by tertiary interactions results in highly active

${ }^{a}$ University of Konstanz, Department of Chemistry, Universitätsstr. 10, 78457, Konstanz, Germany.E-mail: joerg.hartig@uni-konstanz.de; Fax: 497531 885149; Tel: 497531884575

${ }^{b}$ Department of Chemistry and Biochemistry, Freiestr. 3, 3012, Bern, Switzerland

$\uparrow$ Electronic supplementary information (ESI) available: Details of pyrene building block and ribozyme synthesis, as well as ribozyme kinetics. See DOI: $10.1039 / \mathrm{b} 711170 \mathrm{c}$ $\left(k_{\text {obs }} \gg 1 \mathrm{~min}^{-1}\right)$ ribozymes. ${ }^{9}$ In contrast, truncation of stem II has been carried out in minimal hammerhead motifs before. Tuschl and Eckstein reported the need of at least two GC-base pairs in stem II for full activity of minimal hammerhead ribozymes. ${ }^{10}$ In addition to the shortening of stem II in the HHR by omitting base pairs, non-nucleotidic loops have been described as well. Ribozymes with stem II shortened to two base pairs and connected with aliphatic, non-nucleotidic linkers showed drastically reduced cleavage activities. ${ }^{11}$ Here, we introduce variants of a minimal hammerhead ribozyme that contain pyrene-based hairpin mimics displacing stem-loops II and III. In contrast to previous studies, the highly truncated pyrene-modified variants of the hammerhead ribozyme reveal catalytic activities exceeding those of the unmodified, minimal hammerhead motif.

A series of in cis-cleaving minimal hammerhead ribozymes was prepared by automated solid phase RNA synthesis using pyrene phosphoramidite building blocks described earlier ${ }^{12}$ (see Fig. 1). Cleavage rates were determined by $5^{\prime}$-labelling using $\gamma-{ }^{32} \mathrm{P}$-ATP (for details see ESI $\dagger$ ). Drastic truncation of stem-loops in pyrenecontaining variants still maintained catalytic activity (Fig. 2). For example, the pyrene modification allows for shortening of stem II to one basepair (see variant S2-HMR, Fig. 1). The obtained cleavage rates were even higher than for the unmodified ribozyme containing four GC base pairs and the GUUA tetraloop in stem II (see wt-HHR).

The variant S3-HMR with deletions in stem III showed higher activity than the unmodified ribozyme wt-HHR. The observed increase in cleavage rates could originate from a reduced number of alternative folds of the pyrene-capped variants relative to the ribozyme containing all-natural nucleotidic stem-loops. Upon further truncation of the stems, the use of hairpin mimics allows for probing the influence of individual base pairs on the general stability of the catalytically active RNA. A drastic drop in catalytic fitness is observed upon going from S2-HMR to S2.2-HMR, confirming that the corresponding GC-base pair represents an integral part of the conserved catalytic core. ${ }^{13}$ In contrast, deletion of the AU-base pair in the series S3-HMR to S3.2-HMR in stem III results in a variant still showing a $k_{\text {obs }}$ of $0.1 \mathrm{~min}^{-1}$. Interestingly, a drastically shortened variant combining both mimics of stems II and III (S2 + S3 HMR) still exhibits catalytic activity of $0.1 \mathrm{~min}^{-1}$

These data show that pyrene-derived hairpin mimics can be used as probes for studying the contribution of stem-looped elements to the stability of functional RNAs. The incorporated modifications allow for truncation of these elements without altering either the overall stability of the general fold or the catalytic activity of the minimal HHR. The stabilizing effect very likely originates from 


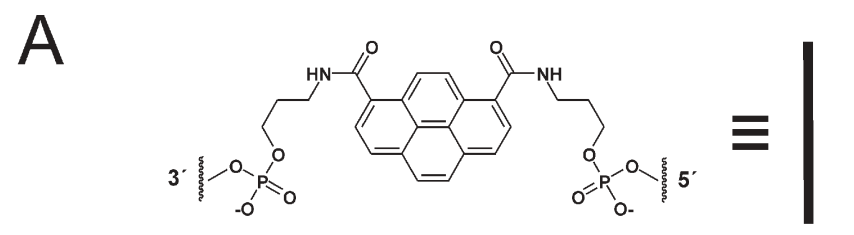

$B$
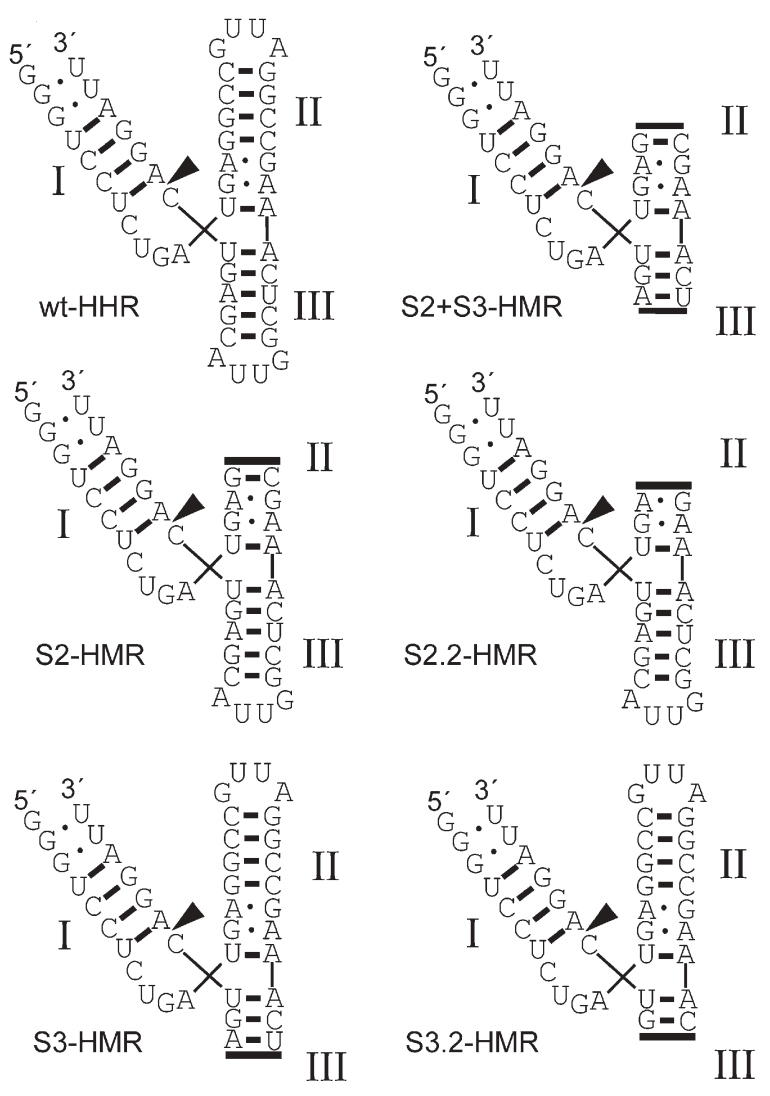

Fig. 1 Pyrene-capped hammerhead ribozymes used in this study. (A) Inserted pyrene building block, symbolized as bold line in (B) which shows wild-type minimal ribozyme and modified variants. The names correspond to the shortened stem-loops, e.g. "S2-HMR" abbreviates "stem 2 hairpin mimic ribozyme".

stacking interactions of the pyrene building blocks with natural base pairs ${ }^{12,14}$ since previously studied aliphatic linkers failed to stabilize the ribozyme fold. ${ }^{11}$ If tertiary contacts of the shortened stems were essential for ribozyme function, catalytic activity should be greatly reduced. With the minimal HHR as model RNA, we find that the major role of stems II and III is the stabilization of the fold since truncation in concert with maintaining structural stability results in variants as active as the unmodified HHR. In the most remarkable case (S2 + S3-HMR), substitution of stems II and III with pyrene-based hairpin mimics results in a considerable reduction of the minimal HHR of up to 18 nucleotides, while catalytic activity is preserved.

In conclusion, we have demonstrated that highly active minimal hammerhead ribozymes are obtained by replacement of stemloops II and III with pyrene. The polyaromatic building blocks allow for deletion of substantial parts of the ribozyme while maintaining the overall stability of the structural fold. Hairpin mimics, such as the pyrene modifications described here, might also be valuable tools for the elucidation of structure-function
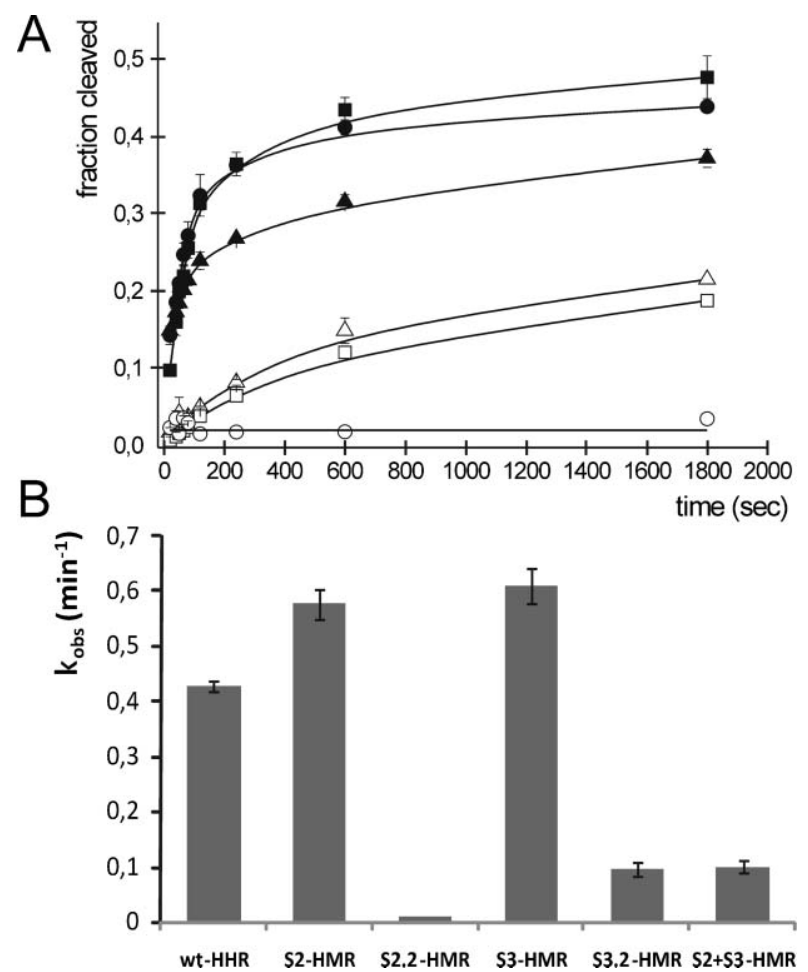

Fig. 2 Kinetic performance of pyrene modified ribozymes. (A) Time course of cleavage reactions. Filled triangles: wt-HHR, filled circles: S2HMR, open circles: S2.2-HMR, filled squares: S3-HMR, open squares: S3.2-HMR, open triangles: S2 + S3-HMR. Details of ribozyme kinetics can be found in ESI. $\uparrow$ (B) Cleavage rates obtained by non-linear regression.

relationships of less well-characterized, functional nucleic acids such as aptamers, recently discovered riboswitches, and other noncoding RNAs.

J. S. H. gratefully acknowledges the VolkswagenStiftung for funding a Lichtenberg-Professorship. R. H. gratefully acknowledges the financial support by the Swiss National Foundation (grant 20020-109482). We thank Markus Wieland for assistance.

\section{Notes and references}

1 R. T. Batey, R. P. Rambo and J. A. Doudna, Angew. Chem., Int. Ed., 1999, 38, 2326-2343.

2 H. W. Pley, K. M. Flaherty and D. B. McKay, Nature, 1994, 372, 111-113; J. H. Cate, A. R. Gooding, E. Podell, K. H. Zhou, B. L. Golden, C. E. Kundrot, T. R. Cech and J. A. Doudna, Science, 1996, 273, 1678-1685; M. Perbandt, A. Nolte, S. Lorenz, R. Bald, C. Betzel and V. A. Erdmann, FEBS Lett., 1998, 429, 211-215.

3 M. Durand, K. Chevrie, M. Chassignol, N. T. Thuong and J. C. Maurizot, Nucleic Acids Res., 1990, 18, 6353-6359; M. Y. X. Ma, L. S. Reid, S. C. Climie, W. C. Lin, R. Kuperman, M. SumnerSmith and R. W. Barnett, Biochemistry, 1993, 32, 1751-1758; W. Pils and R. Micura, Nucleic Acids Res., 2000, 28, 1859-1863; R. Tona and R. Häner, Chem. Commun., 2004, 1908-1909; S. Rumney and E. T. Kool, J. Am. Chem. Soc., 1995, 117, 5635-5646; S. J. Kim, E. K. Bang, H. J. Kwon, J. S. Shim and B. H. Kim, ChemBioChem, 2004, 5, 1517-1522.

4 R. L. Letsinger and T. F. Wu, J. Am. Chem. Soc., 1995, 117, 7323-7328; A. Stutz, S. M. Langenegger and R. Häner, Helv. Chim. Acta, 2003, 86, 3156-3163; Y. Zheng, H. Long, G. C. Schatz and F. D. Lewis, Chem. Commun., 2005, 4795-4797; F. D. Lewis, X. Liu, Y. Wu, S. E. Miller, M. R. Wasielewski, R. L. Letsinger, R. Sanishvili, A. Joachimiak, V. Tereshko and M. J. Egli, J. Am. Chem. Soc., 1999, 121, 9905-9906; 
J. S. Nelson, L. Giver, A. D. Ellington and R. L. Letsinger, Biochemistry, 1996, 35, 5339-5344.

5 J. L. Czlapinski and T. L. Sheppard, ChemBioChem, 2004, 5, 127-129; G. Bianké and R. Häner, ChemBioChem, 2004, 5, 1063-1068.

6 F. D. Lewis and X. Y. Liu, J. Am. Chem. Soc., 1999, 121, 11928-11929; J. B. H. Tok, W. Wong and N. Baboolal, Bioorg. Med. Chem. Lett., 2002, 12, 365-370.

7 O. C. Uhlenbeck, $R N A, 2003,9,1415-1417$

8 C. Hammann and D. M. Lilley, ChemBioChem, 2002, 3, 690-700; K. F. Blount and O. C. Uhlenbeck, Biochem. Soc. Trans., 2002, 30, $1119-1122$.

9 A. Khvorova, A. Lescoute, E. Westhof and S. D. Jayasena, Nat. Struct. Biol., 2003, 10, 708-712; K. F. Blount and O. C. Uhlenbeck, Annu. Rev. Biophys. Biomol. Struct., 2005, 34, 415-440; M. D. Canny, F. M. Jucker,
E. Kellogg, A. Khvorova, S. D. Jayasena and A. J. Pardi, J. Am. Chem. Soc., 2004, 126, 10848-10849; J. A. Nelson and O. C. Uhlenbeck, Mol. Cells, 2006, 23, 447-450; M. Martick and W. G. Scott, Cell, 2006, 126 , 309-320.

10 T. Tuschl and F. Eckstein, Proc. Natl. Acad. Sci. USA, 1993, 90, 6991-6994.

11 J. B. Thomson, T. Tuschl and F. Eckstein, Nucleic Acids Res., 1993, 21, $5600-5603$.

12 S. M. Langenegger and R. Häner, ChemBioChem, 2005, 6, 848-851; S. M. Langenegger and R. Häner, Chem. Commun., 2004, 2792-2793; V. L. Malinovskii, F. Samain and R. Häner, Angew. Chem., Int. Ed., 2007, 46, 4464 4467; I. Trkulja and R. Häner, J. Am. Chem. Soc., 2007, 129, 7982-7989.

13 F. Eckstein, Biochem. Soc. Trans., 1996, 24, 601-604.

14 E. T. Kool, Acc. Chem. Res., 2002, 35, 936-943.

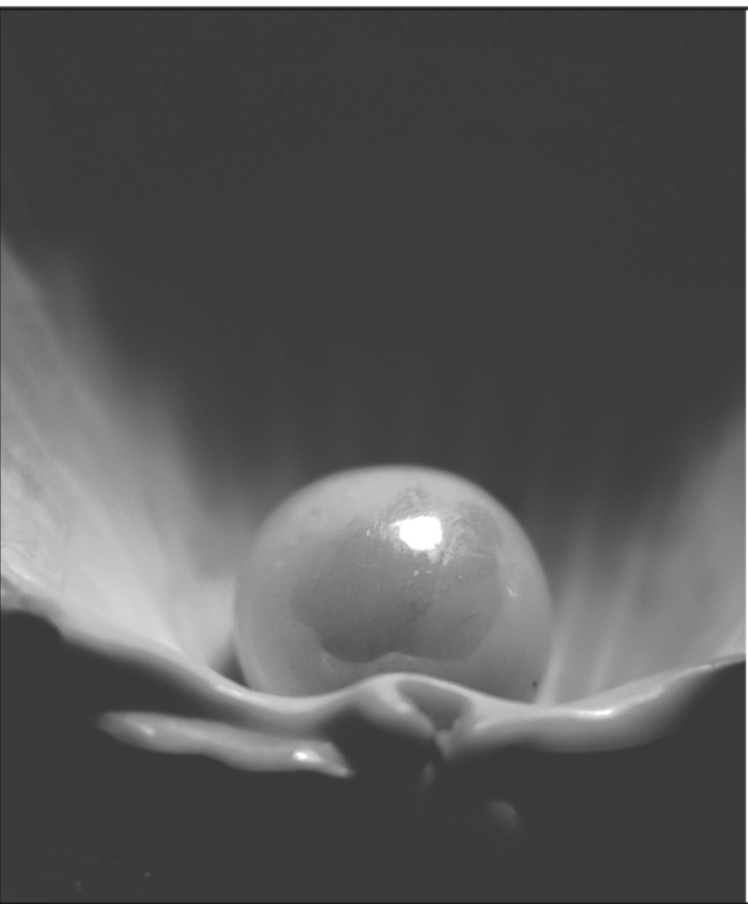

\section{Looking for that SPeCia chemical biology research paper?}

TRY this free news service:

\section{Chemical Biology}

- highlights of newsworthy and significant advances in chemical biology from across RSC journals

- free online access

- updated daily

- free access to the original research paper from every online article

- also available as a free print supplement in selected RSC journals.*

*A separately issued print subscription is also available.

\section{RSCPublishing}

